\title{
Emerging insights from digital solutions in financial inclusion
}

\author{
Sharon Buteau ${ }^{1} \cdot$ Preethi Rao $^{1} \cdot$ Fabrizio Valenti $^{1}$
}

Received: 17 May 2021 / Accepted: 4 July 2021/Published online: 2 August 2021

(C) CSI Publications 2021

\begin{abstract}
In a rapidly digitizing country, Digital Financial Services (DFS) hold the promise of bringing financial inclusion to the last mile. Through the use of DFS, vulnerable and marginalized groups can reduce the risk and cost of using cash, and increase their access to a suite of financial services that would have been otherwise unavailable, or difficult to obtain, such as credit, savings, insurance, and pension. This paper provides an overview of the policy environment regulating digital finance in India as well as presents high-level statistics on the level of digitization across population segments in the country. It then moves on to describe the digital readiness, current usage of digital financial services, and specific issues and solutions for three vulnerable and marginalized groups with high digitization potential: women, micro-entrepreneurs, and domestic migrants. This is complemented by insights drawn from LEAD at Krea University's primary research on these topics. Finally, the paper provides recommendations to accelerate the penetration of digital financial services among vulnerable groups. These include monitoring the implementation of recently introduced policies on data privacy, grievance redressal, and KYC simplification. It is also recommended to develop customized digital financial services that address the unique needs and profiles of vulnerable groups, such as those specifically analysed in this paper.
\end{abstract}

Fabrizio Valenti

fabrizio.valenti@ifmr.ac.in

1 Institute for Financial Management and Research, LEAD At Krea University, IFMR LEAD, 2nd Floor, Buhari Towers, Moores Road, Nungambakkam, Chennai 600006, India
Keywords Digital finance $\cdot$ Financial inclusion $\cdot$ Gender . Women entrepreneurs · Microenterprises · Migrants · Data privacy

\section{Introduction}

\subsection{Digital trends and digital financial services in India}

In recent years, digital technology has accelerated the pace of financial inclusion through the introduction of innovative business models and the progressive digitization of financial systems. In a rapidly digitizing country like India, it is evident that Digital Financial Services (DFS) hold the promise of bringing financial inclusion to the last-mile and reaching the most vulnerable, marginalized, and remote populations of the country. However, several challenges need to be overcome to ensure that these efforts reach the marginalized, and prevent further exclusion.

India's overall rate of adoption of digital tools is the second fastest in the world (trailing behind Indonesia) and, in absolute terms, the number of digital users in India is second only to China [1]. Data from the Telecom Regulatory Authority of India (TRAI) shows that there are 726 million digital users as of September 2020, which is an impressive $278 \%$ growth from September 2016. The increase is driven by mobile internet users, who account for more than $95 \%$ of total internet users. Yet, in a country of over 1.3 billion people, these numbers account for little more than $50 \%$ of the population, which suggests that there is significant untapped potential for further digitization and with the right interventions, the number of "newly digital" users is likely to increase in the coming years. 
These numbers also tell a tale of two countries: internet penetration in rural India, where the majority of the population lives, is only $29 \%$, while it is $92.9 \%$ in urban areas [2]. Similarly, a significant gender gap persists in access to technology [3]. Data on internet penetration, however, does not provide any information on internet usage. In fact, while $51 \%$ of the population has an internet subscription, GSMA data [3] shows that only $26 \%$ of the adult population has accessed the internet using a mobile phone in the past three months, suggesting that the digital footprint of most of India's internet users is limited.

Similarly, despite progress in the adoption of DFS, India is still primarily a cash-based economy. Survey data from 2018 shows that $72 \%$ of all payments in India are cashbased [4], even though the number of account holders increased significantly post the roll-out of the Pradhan Mantri Jan Dhan Yojana (PMJDY). ${ }^{1}$ In November 2016, the Government of India announced the withdrawal of high-value currency notes of INR 500, INR 1000. After demonetisation, the volume of digital transactions increased by $42 \%$ from 672 million in November 2016 to 958 million in December 2016, but this increase was shortlived and since then declined $20 \%$ over two months to 763 million in February 2017 [5]. Despite these initial fluctuations, the usage of digital payments is steadily increasing as demonstrated by UPI transactions statistics in 2021, whose number was over 2.5 billion amounting to almost INR 5 lakh crore (a 15-fold increase since 2018). ${ }^{2}$ However, disaggregated data by income, gender, or population group (e.g., Scheduled Castes and Tribes) is limited, which means that it is difficult to determine how the growth in the adoption of digital payments is distributed among India's population. Recent RBI data ${ }^{3}$ shows that cash is still the preferred mode of payment for retail transactions, especially common, low-value denominations, due to convenience and some persistent last-mile infrastructural issues such as the absence of a functioning POS and slow connectivity. Interestingly, but unsurprisingly, the same survey demonstrated a correlation between income and education vis-a-vis usage of digital payments. The trends in cash withdrawal at ATMs also showcase an increase over the years, with a CAGR of $9 \%$ in volume and $10 \%$ in value [7]. ${ }^{4}$ Still, some evidence suggests that many of the people starting to use digital solutions are likely to maintain their usage, if they have access to sufficient access points and

\footnotetext{
1 Jan Dhan Accounts are a type of free "no-frills" bank account that is offered by banks in India under a financial inclusion scheme backed by the central government.

${ }^{2}$ Data retrieved from the NPCI website on 24 June, 2021.

3 Retail Banking Habits-Evidence from a Pilot Survey [6].

${ }^{4}$ Assessment of progress of digitisation from cash to electronic: https://rbidocs.rbi.org.in/rdocs/Publications/PDFs/CASH B74203395BD64E2ABC1BD5F68D8AEF13.PDF.
}

training [8], suggesting that over time it is reasonable to expect a growing usage of digital payments even among low-income and low-literacy groups.

Promoting the transition to an economy that relies less on cash, comes with some very tangible benefits. The Reserve Bank of India (RBI) estimates the cost of currency operations to be around $\$ 3.5$ billion every year and the World Bank estimates that the Indian Government can save around $1 \%$ of GDP annually by just digitizing cash-based subsidies. Digitizing financial transactions can also benefit the low-income population in many ways:

1. Digital transactions can translate into significant savings on cost and time spent in travelling to physical bank branches to access money, in turn increasing the time that the poor can spend on productive tasks.

2. Digital transactions can help the poor opt-in for commitment savings products which can assist them in overcoming practical and behavioral barriers to saving [9].

3. While transacting in cash takes time, digital transactions are instantaneous and thus most suited in emergency situations such as health shocks and natural calamities.

4. Security is a concern when handling large amounts of cash, especially for regular cash payments and particularly in remote areas. Digital payments ensure safety of storing and transporting cash for the poor [10].

The dominance of cash in low-income settings not only makes it difficult for poor households to manage their finances, but also precludes them from accessing formal financial services. This can also result in exclusion from social protection systems considering India's focus on the use of Direct Benefit Transfers (DBTs) to plug leakages in the delivery of government schemes and entitlements. The COVID19 crisis provides a clear example of this issue. During the first wave of the COVID-19 pandemic in March 2020, the Government of India introduced several tranches of relief measures ${ }^{5}$ consisting of both cash and in-kind transfers. Cash transfers under the Pradhan Mantri Garib Kalyan Yojana (PMGKY) and Atmanirbhar Bharat schemes relied on the existing infrastructure of Aadhaarlinked Jan Dhan Accounts to disburse these benefits. As a result, citizens without access to formal financial services were automatically excluded from receiving these benefits. On the other hand, citizens that had access to formal finance, relied heavily on digital tools to withdraw these relief funds. The National Payment Corporation of India (NPCI) reported 403 million approved Aadhar enabled Payment System (AePS) transactions in April 2020, as

\footnotetext{
5 https://www.mohfw.gov.in/pdf/MoFPMGaribKalyanYojanaPack age.pdf.
} 
compared to roughly 172 million transactions in March 2020. 6

The fintech industry has the potential to reshape the financial inclusion landscape in India. Fintechs address key access issues by reducing cost barriers for delivering financial services to remote rural areas and to marginalized customer segments such as women and migrants. Through innovative solutions, they provide suitable 'bite-sized' solutions to low-income customers and create digital identities and trails that can significantly reduce information asymmetries for service providers. The success of Fintech companies, however, is conditional on the capacity and willingness of citizens to adopt the services they offer, as well as the Fintech companies being able to adequately manage last-mile delivery issues. The next section explores the digital readiness and access to digital financial services of three population segments of particular interest: women, micro-entrepreneurs, and domestic migrants. While we present results and insights about these groups separately, they often overlap. This does not take away from the conclusions provided below, but this sort of intersectionality should be taken into consideration when developing digital financial products for these groups.

\section{Digital readiness and digital financial inclusion of vulnerable groups}

Understanding issues in the context of their real-world settings helps to gain deeper insights on granular aspects at the intersection of digital technology, finance and inclusion. We highlight perspectives from three vulnerable segments in India described above, women, micro enterprises and domestic migrants. Each segment has its own distinct challenges, where technology has the potential to create positive impact, provided it systematically addresses the complex multidimensional bottlenecks.

\subsection{Women}

GSMA's 2019 Mobile Gender Gap Report highlights that only $16 \%$ of Indian women are mobile internet users against $36 \%$ of men. ${ }^{7}$ Gender gaps also persist in the usage of mobile phones for financial transactions (9\% women as compared to $16 \%$ men) and in debit card ownership (24\% more by men). ${ }^{8}$ Social norms play an important role in determining women's access to digital tools. Evidence

\footnotetext{
${ }^{6} \mathrm{https} / / / \mathrm{www}$.livemint.com/opinion/columns/fix-the-problems-inaadhaar-based-cash-transactions-11588930862806.html.

7 Further disaggregation of this data, for example by education, income, and social group is not available, which means that the relation between the intersection of gender and other vulnerabilities, and access to technology is still unclear.
}

suggests that women's usage of technology is perceived negatively through the lenses of traditional norms, since it is associated with promiscuous behaviors [11-14]. This leads women who might be concerned about their reputation to refrain from using digital tools in the first place and many others can only use them under strict supervision [14]. This latter issue limits the gender transformative potential of digital tools, a large part of which is predicated on the premise that digital financial services can help women increase control and privacy over their financial resources [15].

Still, it is reasonable to expect that the penetration and adoption of digital tools among women, especially those living in rural areas, will increase. This group is characterised by a low, but steadily increasing, internet penetration rate and is being targeted by a number of interventions from the central and state governments that can lead to higher digitisation. For example, the government has opted to deliver some of its COVID-19 relief package through direct cash transfers to women-owned Jan Dhan Accounts. A study by Yale's Economic Growth Center (EGC) suggests that while this strategy is likely to lead to significant exclusion errors [16], it is also reasonable to assume that it might have incentivised some women to conduct digital transactions. Among rural women, Self Help Group (SHG) members merit a special mention. ${ }^{9}$ As highlighted in a report by LEAD at Krea University [17], central and local governments are promoting digital solutions to streamline the work of these groups (electronic book-keeping, MIS systems), encourage the adoption of financial services, improve communication and learning, as well as introduce new livelihood opportunities.

Arguably, these efforts can have positive digitisation effects on the groups themselves as local institutions and on individual group members as well. Furthermore, many agent-based models that are being implemented across the country are incentivising the adoption of digital tools among rural women directly (e.g. Internet Saathi ${ }^{10}$ ) and indirectly (e.g. Bank Sakhi ${ }^{11}$ ).

Ensuring that women have better access to digital financial services has the potential to greatly enhance economic growth and prosperity. Focusing, as an example,

\footnotetext{
$\overline{8}$ Digital Inclusion via Education project: https://www.gfsi.in/divedigital-inclusion-via-education/.

${ }^{9}$ Current data from the National Rural Livelihoods Mission pegs the total number of SHGs at $6,965,200$ for a total $75,859,685$ members.

${ }^{10}$ Internet Saathis are agents trained under a programme to improve digital literacy among women in rural areas in India, in order to bring them online. The programme is a joint initiative of Google India, Intel and Tata Trusts.

${ }^{11}$ Bank Sakhi are SHG members who have been trained to be Banking Correspondents that can promote financial literacy, help others open bank accounts and perform basic CICO transactions.
} 
on women entrepreneurs, evidence suggests that most female entrepreneurs usually depend on their own savings, loans from family and friends, or micro-loans to finance their business needs as demonstrated by data from the 6th Economic Census. Specifically, 79 percent of female entrepreneur-led organisations finance their enterprises using their own capital, since banks and other financial institutions remain unsure of the business models and the potential or guaranteed returns on loans. Hence, for the 58 percent female entrepreneurs in India who start businesses between the age of 20-30 years, the main source of funds is self-financing or the use of inherited capital assets or physical property that can be mortgaged. The case study below highlights a few of the multiple potential and challenges in a sector that provides employment to a significant portion of women.

\subsubsection{Technology, gender, artisans and inclusion}

The handicrafts sector is the single largest non-farm employment sector in rural India and has a high percentage of women. The only reliable figures on the market side are the value of exports of handicrafts which stood at USD 3.39 billion in FY20 (till February 2020). The Indian craft industry is highly fragmented with over 67,000 exporters/export houses promoting regional art and craftsmanship in domestic and global markets.

Catalyst Atal Incubation Centre (AIC), set up under a grant from Niti Aayog's Atal Innovation Mission, focuses on inclusive tech solutions and enabling start-ups that work with marginalized segments in the craft sector. Catalyst AIC conducted a scoping study d on operational and digital readiness of artisans communities in the state of Rajasthan and Uttar Pradesh. The initial scoping study aims to map their overall operational aspects, as well as their readiness for technology-embedded solutions. Using a purposeful sampling approach based on lists shared by key stakeholders from grassroot organizations, 874 artisans were interviewed for the scoping study. Among them, the majority $(75 \%)$ were women. In terms of the format, the overwhelming majority of artisans are working in a homebased setup (89.49\%), without any registration (4.23\%).

Women do have some authority in day-to-day expenses in the household, but few $(23 \%)$ have a separate financial asset in their name. Furthermore, women typically spend savings on household requirements or children's education. Access to mobile phones varies, and is often shared within the household. Mobile phones are primarily used for communication or entertainment purposes when women are able to access the internet. The applications commonly used are WhatsApp, YouTube and Facebook mostly for communications or entertainment, while only $7 \%$ of respondents use payment apps. Internet access $(58 \%)$ is also limited and most (67\%) responded not having an email account.

$50 \%$ of the respondents do not have a separate bank account for business purposes. About a third of the respondents do not have a mobile linked account. Furthermore, formal business credit is scarce. Most respondents prefer taking cash advances for their orders. They hardly take any working capital loans and whenever they do $68 \%$ of the time they opt for informal sources with interest rates ranging from 12 to $36 \%$ per annum. Only half of the artisan maintain any accounts and among them only $25 \%$ maintain records for internal transactions. $94 \%$ of them make accounts on paper only. $30 \%$ provide bills on purchase.

There is high reliance on middle-men and traditional networks for sales such as crafts melas. Initial transactions are mostly preferred in-person. The vast majority (98\%) do not sell products directly online. Even though $16 \%$ received training to sell online, most have not been able to use it.

From the initial scoping insights above a few clear trends emerge. There are several interdependent challenges that need to be resolved to optimize the impact of technology, as well as to ensure that it does not lead to further exclusion.

To achieve gender parity, it is imperative that women are enabled to access and use DFS and women entrepreneurs have access to digital credit. DFS, in fact, can help overcome some of the traditional issues linked to accessing financial services, such as mobility restrictions, burden of care, and cultural biases.

\subsection{Merchants and microenterprises}

Access to credit remains a barrier for the growth of the MSME sector in India [18]. Microenterprises face a \$230 billion credit gap ${ }^{12}$ despite accounting for lower non-performing assets. The lack of capital is debilitating as it presents a significant barrier for growth of such enterprises. As a result, majority of the credit needs to microenterprises are met by informal sources of finance and they remain outside the ambit of formalization, thus fueling further exclusion.

In both rural and urban areas, a recent study completed by [19] shows that, despite increasing levels of digital payments adoption across value chains, transactions between merchants and consumers remain largely cashbased.

\footnotetext{
12 https://www.ifc.org/wps/wcm/connect/03522e90-a13d-4a02-87cd9ee9a297b311/121264-WP-PUBLIC-MSMEReportFINAL. pdf?MOD=AJPERES $\&$ CVID=m5SwAQA.
} 
At the same time, the COVID-19 crisis has increased the demand for digital payments among retail customers in certain sectors (groceries, pharmacies, utilities to name a few) in both rural and urban areas. ${ }^{13}$ Whether this emergency-driven increase in uptake will lead to long-term behavioral changes or it will wane off as it happened after demonetization is still to be determined. Yet, merchants have increased their usage of e-commerce platforms, with Goldman Sachs ${ }^{14}$ noting that the COVID19 pandemic drastically accelerated growth in this sector and estimated a compound annual growth of $81 \%$ for online grocery through 2024. Whether small retail shops will be able to benefit from this transition or they will be squeezed out by larger players, however, is not yet known and will need to be closely monitored in the coming years to ensure a fair and inclusive shift to a more digital economy.

Increased adoption of digital payments can help financial institutions assess the credit worthiness of micro and small entrepreneurs that might lack a formal credit history. This model has been adopted successfully in Central and South America, by tying credit to both sale invoices/receipts or the entrepreneur's estimated inputs or inventory [20]. However, loans of very low ticket size (nano-loans), which are normally required by micro and small entrepreneurs to cover for recurring working capital needs, might be offered more profitably through unsecured credit modes or, in partnership with a telecom company, through an analysis of customer Call Detail Records (CDR). This approach allows the lender to quickly gauge how regularly, for example, prospective customers top up their credit and/ or if they pay their bills on time, and has been demonstrated to be an effective mean to predict credit-worthiness [21-24]. Nano loans are normally offered by Fintech companies since technology, arguably, is a crucial factor to lower the cost of disbursing small-ticket size loans and ensure the profitability of this type of business. However, many of the solutions currently available in India to receive individual nano loans, such as MoneyTap or PaySense, require a minimum level of monthly earnings, ranging from 15,000 to 20,000 rupees per month. Home-based and informal-sector micro-entrepreneurs may find it difficult to meet this eligibility criteria.

This approach to lending is not, however, without risks for both borrowers and service providers, as some reports highlight that the current regulatory framework of Digital Lending Apps (DLAs) still allows for a degree of lack of

\footnotetext{
13 https://community.nasscom.in/communities/digital-transforma tion/fintech/digital-payments-india-short-to-medium-term-effects-ofcovid-19.html.

14 Outlook India, July 21, 2020. "India e-commerce to grow 27\%; Reliance to capture half of online grocery sales: Goldman." https:// www.outlookindia.com/newsscroll/india-e-commerce-to-grow-27-reli ance-to-capture-half-of-online-grocery-sales-goldman/1899640.
}

transparency on the interest rate charged, hidden charges and deductions and on the collection methods deployed [25].

\subsubsection{Technology and the micro-merchant ecosystem in india}

The Indian MSME sector contributes about 30\% towards the GDP through its national and international trade. It is unique in its long fat tail of relatively unproductive, subsistence micro enterprises, which are non registered or informal, new-to-formal-credit, and characterized by low growth and employment per unit. According to the sixth Economic Census, $69 \%$ of these enterprises are unregistered. Thus showing that a majority portion of one of India's largest and most important sectors are out of reach of the government and most likely not under the purview of formal finance institutions.

While technology can have multifold benefits for MSMEs, from improving access to finance, expanding market reach, enhancing efficiency to reducing costs, most MSMEs are far away from reaping these benefits of digitalisation.

To understand the on-the-ground adoption and usage of digital platforms, in 2017, LEAD surveyed 547 merchants across the five cities of Jaipur, Kanpur, Indore, Nagpur and Surat and across twelve different business categories. The survey sought to understand the business profiles of merchants in terms of their cash flows and asset ownership; their credit profiles in terms of previous and current borrowings, and their adoption and usage of digital financial services (DFS).

Micro-merchants operate in an ecosystem where cash is the primary mode of transaction-for even payments to suppliers, and more importantly, the preferred mode for a majority of the clientele.

However, this is particularly interesting because these merchants appear to be digitally ready, i.e. they have access to a smartphone and/or some form of digital payment system. The vast majority of the shop owners interviewed in the study stated that demand for digital payment from consumers can trigger adoption.

There are also significant infrastructural barriers to adoption such as weak internet connectivity (only 38\% of non-adopters had access to the internet) as well as perception barriers among non-adopters (65\% did not consider DFS to be beneficial to their business). A combination of strategies, both from a service provider perspective and generally from the government, could address such barriers and encourage adoption. These include reducing or fully eliminating trial costs, enhancing digital financial capabilities, creating access 
to network and internet connectivity, and target supply chain based financing. ${ }^{15}$

These findings are confirmed by more evidence collected by LEAD at Krea University under its Catalyst initiative, along with People Research on India's Consumer Economy (PRICE). As part of a study on small merchants and their digital financial behavior in Jaipur, it was observed that while $42 \%$ of merchants have adopted digital payment mechanisms, 55\% remain non-adopters primarily due to lack of customer demand, low awareness and cost of adoption.

Ensuring that microenterprises are formalized is an essential step in promoting the adoption of digital solutions. In this regard, apart from expanding India's tax base, the introduction of the Goods and Services Tax (GST) has resulted in over 9.2 million enterprises being GST registered. ${ }^{16}$ In addition to becoming formalised, a significant proportion $(47 \%)$ of microenterprises are also using digital tools for business processes, sales and payments. ${ }^{17}$ Such a digital transformation of internal operations will ensure that they are well placed to use digital lending platforms to address their growing credit needs.

\subsection{Domestic migrants}

The precarious financial conditions of domestic migrants in India have been in the spotlight following the implementation of lockdown measures in March 2020, which led hundreds of thousands of migrant workers to leave their place of work and take a long and arduous journey back home-facing deprivations, challenges, and hazards along the route. India's domestic remittance market is the second largest in the world and it is estimated to be worth USD 10 billion, with over 139 million migrants contributing to it. ${ }^{18}$ Even before the COVID-19 crisis, domestic migrants were increasingly using formal banking channels to send remittances, but these transactions accounted for only $30 \%$ of the total share of remittances. However, these statistics are over a decade old and more recent data suggests that the use of formal remittances has increased, as demonstrated by a recent survey conducted by LEAD at Krea University. The same survey, however, also demonstrates that while the use of formal remittance channels is high,

\footnotetext{
15 http://www.ice360.in/news/mapping-the-merchant-s-mind-an-ana lysis-of-digital-payment-behaviors-by-fixed-store-merchants-injaipur.

16 Economic Survey, 2017-2018, Government of India.

17 Digital Lending, The Boston Consulting Group, retrieved from https://image-src.bcg.com/Images/BCG-Digital-Lending-Report_ tcm9-197622.pdf.

18 Data from the 2011 Census 2011 and Tumbe [26], Remittances in India: Facts and Issues.
}

migrants and their households still rely mostly on informal credit and savings sources.

Arguably, the use of formal remittance channels should allow migrant households to fully transition to formal financial services fairly easily as they already have a track of transactions. These could be used, for example, to allow access to credit products tailored to the needs of migrants and their households (for example, repayments could adapt to the income fluctuations linked to migration cycles). Intuitively, given the transient nature of migration, digital financial services seem particularly apt to meet the needs of migrants and their households remotely. However, while evidence suggests that migration increases the financial sophistication of the migrant [27], if products are not tailored to the specific conditions of migrants and their households, financial products such as savings, pension, and insurance are unlikely to be picked up by this population. For instance, a recent policy change introduced by the Reserve Bank of India has significantly simplified the $\mathrm{KYC}$ process for migrants, who faced issues in complying with KYC norms since they did not have access to a permanent address proof at destination. The government has eased KYC norms for migrants to open bank accounts by allowing them to provide a self-declared local address as sufficient proof of residence in case it is different from the address mentioned in Aadhaar document (Department of Revenue's notification in November 2019). These changes are consistent with the recommendations presented by Bailey et al. [28] that argue that KYC norms in India are more stringent than the prescriptions of the Financial Action Task Force and, thus, lead to unnecessary exclusion from the formal financial sector. As the COVID-19 pandemic struck shortly after these measures were introduced, it is still early to assess their success in expanding access to financial services among migrants. The RBI's directive ${ }^{19}$ to move to digital KYC for ease of access to DFS during the pandemic further accentuates the need for better data privacy protocols in order to protect the vulnerable segment of the population.

\subsubsection{Domestic migrants and formal finance: progress and potential}

The Economic Survey of India 2017 estimates inter-state migration in India at close to 9 million annually between 2011 and 2016, while Census 2011 pegs the total number of internal migrants in the country (accounting for interand intra-state movement) at a staggering 139 million.

Several push and pull factors motivate people to migrate, including economic factors, which are a key driver

\footnotetext{
${ }^{19}$ RBI KYC Directive (updated on May 2021): https://www.rbi.org. in/CommonPerson/english/scripts/notification.aspx?id=2607.
} 
of migration. It also constitutes one of the most widely used financial strategies to enhance and stabilize household income [29]. As a result, estimates place the size of the domestic remittance market in India at \$24 billion, the second highest in the world after China.

Estimates from 2011 [26] show that only 30\% of the total domestic remittance flows in India is routed through formal channels. A study conducted by LEAD at Krea University in 2011 confirmed the low usage of formal remittances- $57 \%$ of respondents $(n=274)$ used informal mechanisms to transfer money. However, the same study showed the potential for formalization of this type of transaction: half the sample would have preferred to send their remittances through bank transfers. However, lack of documentation and high costs, mostly in terms of time and, thus, lost salaries, act as barriers for using formal channels. In the same survey, migrants mentioned that security and speed of delivery are the two most important factors in choosing their preferred method of remittance, thus further showing potential for formalization.

Preliminary findings from a forthcoming study by LEAD at Krea University show that this transition to formal remittances may be well underway. In the study, which seeks to unpack financial decision-making in migrant households, surveys were administered to 649 migrants and 494 members of migrant households (total $n=1143$ ). Among other results, it was observed that over $80 \%$ of the sample used formal channels to submit and receive remittances, a vast improvement over what was observed in 2011. A plausible explanation for this discrepancy is that much of this literature is more than a decade old. Given the advancements in financial inclusion in India, particularly with the advent of the JAM trinity, migrant preferences have shifted towards formal modes like bank transfers with increased access. Results from the study are forthcoming and need to be validated by surveys with more representative samples.

However, we find that only a small proportion of respondents (3\% of the migrants) reported having borrowed from financial institutions. As the data was collected nine months after the beginning of the COVID-19 pandemic, it is possible that this result might be caused by formal credit being harder to obtain in this period. However, this result suggests that the process of formalization of the financial behavior of migrants and their households is incomplete. Arguably, the progress already achieved with remittances can be used as a springboard to further promote the adoption of formal financial products, if they are tailored to the needs and characteristics of migrants and their households. Digital financial services and Fintech companies are very well positioned to support progress in this sector as they have the potential to lower the costs of developing and delivering customized financial products.

\subsection{The policy environment and data protection}

On the regulatory side, the government has been building a comprehensive enabling policy environment as well as developing policies that directly or indirectly promote digitisation. Through the Pradhan Mantri Jan Dhan Yojana (PMJDY) it has set up 422 million ${ }^{20}$ savings bank accounts along with services to activate these accounts. At the same time, the deregulation of banking licenses has not only opened up the traditional banking sector to newer, nimble players but planted the seeds for new types of banking institutions-notably, small finance banks and payment banks-which can reach and serve the lower economic strata more effectively. In the social protection ecosystem, the Direct Benefit Transfer program is digitizing major government to consumer payments with a $50 \%$ increase in efficiency savings documented. Other initiatives include the Bharat Bill Payment System for centralized online and offline payments of utility bills, school fees, taxes, and Digital India, an umbrella for approximately $\$ 15$ billion worth of schemes to provide digital services to citizens including broadband in rural areas, public wi-fi, and e-signatures.

At the center of these initiatives stands India Stack, the country's digital financial infrastructure, which was first established in 2009. Founded on what is now an almost universal $^{21}$ penetration of the country's unique biometric ID system (Aadhaar), India Stack has four layers: presenceless layer, cashless layer, paperless layer, and a consent layer. Over the years it has become the largest open API in the world, with the gradual introduction of important components such as the Aadhaar Enabled Payment System (AePS), Universal Payment Infrastructure (UPI), Digilocker, and more recently, Account Aggregators (AAs). Account Aggregators make a fundamental contribution to the consent layer of India Stack, functioning as "blind" intermediaries ${ }^{22}$ between Financial Information Users (FIUs) and Financial Information Providers (FIPs) that, conditional on customers giving explicit consent, fetch and deliver data between Financial Service Providers (FSPs). As these institutions are still nascent, their impact on improved data usage for financial inclusion is still uncertain [30], but their introduction signals an increased policy interest in strengthening data protection and consent, confirmed by the recently drafted Personal Data Protection

\footnotetext{
${ }^{20} \mathrm{https} / / / \mathrm{ww} w$. thehindubusinessline.com/money-and-banking/jandhan-accounts-see-unusual-surge-in-total-balance-in-march/arti cle34296858.ece\#: :text=The\%20total\%20balance\%20of\%20Jan, crore $\% 20$ to $\% 20 \% \mathrm{E} 2 \% 82 \% \mathrm{~B} 91 \% 2 \mathrm{C} 500 \% 20$ crore.

21 According to government data, 1.25 billion Indians have an Aadhaar number, i.e. $96 \%$ of the population.

${ }^{22}$ Meaning that they cannot see, store or analyse customer data.
} 
Bill $^{23}$ (PDPB). With regards to the implications of the PDPB on financial services and financial inclusion, recent news articles ${ }^{24}$ reported that RBI is seeking an exemption from the application of the law as well as trying to avoid financial data from being classified as sensitive personal data. This amendment would be in line with similar international laws as both European and British data protection laws exclude central banks from their purview and also do not classify financial data as sensitive data. The proposed PDPB is expected to be of particular significance for Fintech companies, especially those working with APIbased interfaces that fall outside the purview of Account Agrregators and especially if financial data will remain categorized as sensitive personal data. If that were to be the case, firms would not be allowed to view or process the financial data of their customers after meeting the purpose for which it was initially shared, unless citizens give their explicit consent. Potentially, in its most stringent application, this regulation might limit firms' ability to improve financial products and develop new ones. Additionally, it is very likely that the PDPB will lead to the establishment of consent managers, firms that will act as intermediary data fiduciaries similar to AAs. However, the operational details of how these entities will function is still uncertain, as well as their regulatory framework.

\subsubsection{Grievance redressal}

The High-Level Committee Report on Deepening Digital Payments constituted by RBI in 2019 suggested a few targeted solutions for some of the existing problems in the DFS architecture in India. These include enabling KYC data sharing, incentivising the use of digital payments, promoting financial literacy through frontline staff, among broader ecosystem level solutions. Notably, the committee stressed on ensuring dispute resolutions and monitoring transaction failures, considering that it constitutes a key factor for the low usage of DFS. Evidently, while India's digital financial ecosystem has been growing and improving both technically and operationally, transaction failures remain a problem. For instance, during the first phase of the COVID-19 pandemic, AePS transaction failures have increased from 49\% in March 2020 to 60\% in April 2020, ${ }^{25}$ mostly due to biometric mismatches and timed-out transactions. Clearly, this creates significant trust issues,

\footnotetext{
23 The bill, published in December 2019, is currently being reviewed by a Joint Parliamentary Committee and is expected to be approved soon

${ }^{24}$ https://www.hindustantimes.com/india-news/rbi-seeks-exemptionfrom-data-protection-law/story-kwQzNs614s0C56VK6HTCJP.html.

25 https://theprint.in/opinion/why-more-smartphones-and-bankaccounts-havent-brought-financial-digital-inclusion-in-india/327919/.
}

especially among first-time users and those who are in the early stages of the adoption journey.

High transaction failures are particularly problematic for Fintech companies. An experiment conducted with eMitras (e-governance kiosks) in Rajasthan, ${ }^{26}$ as part of the Catalyst ${ }^{27}$ program, found that technical errors at the service provider's end-such as transaction failures which are either bank related or eMitra portal related, are a critical hurdle in digital payment uptake. Under the eMitra model, the payment process first requires the money to be debited from the customer's account through the PoS machine. The slip generated has a particular transaction number that needs to be entered on the portal, to link the specific payment to a particular bill. Often, while the amount is debited, the transaction fails to validate on the portal which leaves the entrepreneur at the point of sale with limited choices, the most appropriate being cancelling the transaction which initiates a refund of the amount to the customer. While refunds are typically processed in one or two days, in some cases, customers have waited up to a month to get their refund. In order to build trust around the solution, it is important that any query or issue is addressed and resolved at the earliest. While the number of such failures, particularly where the money is debited but the transaction has failed, is low, they do impact the motivation of both the customer as well as the eMitra entrepreneur to continue transacting digitally. These customers would otherwise revert to cash as the preferred mode of payment.

\section{Conclusions and policy recommendations}

In a rapidly digitizing country, digital financial services and fintech companies hold the promise of bringing financial inclusion to the last mile. Ensuring that vulnerable and marginalized groups have access to digital finance, can substantially reduce the time spent on getting cash as well as the risks associated with holding it, and it can facilitate their inclusion in formal financial services, unlocking access to a number of financial products including credit, savings, insurance, and pension.

While expanding access to digital financial services is important, it is evident through the examples brought forward by this paper that it is not enough to ensure usage. It

\footnotetext{
${ }^{26}$ eMitra is a Government of Rajasthan e-governance platform that provides government to customer $(\mathrm{G} 2 \mathrm{C})$ and business to customer (B2C) services to citizens.

${ }^{27}$ Catalyst is an initiative funded by the United States Agency for International Development (USAID) under the mSTAR Program, through funding provided to FHI 360. Housed within LEAD at Krea University at the Institute for Financial Management and Research, the initiative aims to expand digital payments and financial inclusion in India.
} 
has been observed, for example, that many migrants use formal banking services to send remittances back home, but rely on cash and informal services for payments, savings, and credit. This gap between access and usage can in part be attributed to a lack of customized solutions for this population. For instance, migrants require credit and access to liquidity for very specific (often low-value) purposes (e.g., financing their travel from source to destination). Similarly, they need other financial services, like housing credit, or health insurance for limited periods of time, depending on their migration cycle and preferences. Leveraging the flexibility and cost-effectiveness of digital financial services could help develop and deploy such solutions. Similarly, it has been observed that women and women entrepreneurs could benefit from some of the innovations that could be introduced by tailored credit solutions that, leveraging the potential of digital solutions, could overcome traditional access barriers such as mobility and lack of collateral and/or credit history. The latter could be addressed, for example, through CDR-based nano loans.

Additionally, insufficient 'push' from customers prevents microenterprises and merchants from fully transitioning to digital payments, despite high levels of digital readiness. Part of this lack of demand can be attributed to concerns from the customer's side about transaction failures. Strengthening grievance redressal mechanisms, is thus fundamental to increase citizens' trust in and usage of digital financial services, as recommended by RBI's 2019 High Level Committee report on Deepening Digital Payments. The same report recommended easing KYC regulations, an advice that was implemented towards the end of 2019 itself. Measuring the success of this initiative is not simple as its results have been evidently affected by the COVID19 outbreak.

As fintechs innovate to expand financial services access to vulnerable sections of the population, it becomes imperative for the government and regulators to introduce enabling policies for incubating such ideas. Regulatory sandboxing is a way to encourage such innovations in this space. Regulatory bodies such as RBI, SEBI and IRDAI have introduced such sandboxes for developing and testing innovative financial products in controlled environments; however, there is still a need to focus on inclusion as a key outcome [31]. This will allow regulators to support changes in the financial inclusion space while having the option to collect evidence regarding the implications of such measures. A sandbox approach can reduce entry barriers for fintechs by reducing the hassles related to formalization such as registration and tax filing, which in turn will bring down the cost of their product offerings. This will increase trialability among merchants and end customers.

Lastly, encouraging the shift to digital financial services, will require a coordinated effort to educate, handhold and encourage vulnerable customers to accept and use such solutions. Showcasing the benefits alone is not enough. There is a need to identify first movers and evangelists from within communities to articulate their first-hand experience which will build trust for a new user to adopt. Fintechs and solution providers (and the government) should provide assistance at the last-mile to onboard these customers and guide them through their usage journey.

Recent years have seen significant progress in the penetration of digital financial services, supported by an enabling policy environment, improvements in the digital infrastructure, reduced costs of the technology and connectivity, increased penetration of digital tools, and growing digital literacy. Yet, much can still be done to accelerate progress and the rest of this section will be devoted to present a few policy recommendations and outline open research questions.

As the number of digital users increase, issues of data privacy are becoming increasingly relevant. The introduction of Account Aggregators and the Data Protection Bill 2019 signal the regulator's intent to protect citizens' privacy to the greatest extent possible. As these institutions are nascent, in the coming months it will be important to closely monitor their rollout and implementation to timely identify emerging issues and solutions. However, informing citizens of their rights and how such institutions work appears to be an immediate unaddressed need. Ensuring that citizens belonging to vulnerable and marginalized groups, that are already less digitally and financially sophisticated, will be particularly challenging and will not be achieved unless the mandate to take up this responsibility is clearly assigned to an institution.

\section{References}

1. Jacques B, James M, Jonathan W (2019) Digital India Report. McKinsey Global Institute. http://www.mckinsey.com/ /media/ mckinsey/business $\% 20$ functions/mckinsey $\% 20$ digital/our $\% 20$ insights/digital\%20india\%20technology $\% 20$ to $\% 20$ transform $\%$ $20 \mathrm{a} \% 20$ connected $\% 20$ nation/digitalindia-technology-to-trans form-a-connected-nation-full-report.ashx

2. Deloitte (2020) Broadband for inclusive development. CII. http:// www2.deloitte.com/content/dam/Deloitte/in/Documents/tech nology-media-telecommunications/in-ra-cii-broadband-reporttelecom-convergence-summit.pdf

3. Rowntree O (2019) The Mobile Gender Gap Report. Connected Women, GSMA. http://www.gsma.com/mobilefordevelopment/ wp-content/uploads/2019/02/GSMA-The-Mobile-Gender-GapReport-2019.pdf

4. Capgemini, BNP Paribas (2018) Worldpay Global Payments Report. http://worldpaymentsreport.com/wp-content/uploads/ sites/5/2018/10/World-Payments-Report-2018.pdf

5. Nair S, Korada S, Rao P (2018) Understanding the Impact of Demonetization on Bank Account Holders from Low Income Households. IFMR LEAD. http://ifmrlead.org/files/IFMR- 
LEAD-Demonetization-Study-Final-Report.pdf. Accessed Apr 2018

6. Pradip B, Jolly B, Ram PR (2021) Retail Payment Habits in India - Evidence from a Pilot Survey. RBI Bulletin. http://rbidocs.rbi. org.in/rdocs/Bulletin/PDFs/04AR_26042021C7C9371E047E4AF CACA834ECCBBB1152.PDF. Accessed 26 Apr 2021

7. Reserve Bank of India Department of Payment and Settlement Systems Central Office, Mumbay (2020) Assessment of the progress of digitisation from cash to electronic. https://rbidocs. rbi.org.in/rdocs/Publications/PDFs/CASHB74203395BD64E2AB C1BD5F68D8AEF13.PDF. Accessed 24 Feb 2020

8. Microsave (2017) Demonetisation and Digitisation - A Diagnostic Study. http://www.microsave.net/wp-content/uploads/ 2018/10/Demonetisation_and_Digitisation_Diagnostic_Study.pdf. Accessed Mar 2017

9. Karlan D, Ratan AL, Zinman J (2014) Savings by and for the poor: a research review and agenda. Rev Income Wealth 60(1):36-78

10. Wright GA, Mutesasira LK (2001) The relative risks of informal savings. MicroSave Research Paper

11. Allendorf K (2013) Schemas of marital change: from arranged marriages to eloping for love. J Marriage Family 75:453

12. Arora P, Scheiber L (2017) Slumdog romance: Facebook love and digital privacy at the margins. Media Cult Soc 39:408

13. Bell G (2006) The age of the thumb: a cultural reading of mobile technologies from Asia. Knowl Technol Policy 19:41

14. Barboni G, Field E, Pande R, Rigol N, Schaner S, Troyer Moore, C (2018) A tough call: understanding barriers to and impacts of women's mobile phone adoption in India. Evidence for Policy Design, Harvard Kennedy School. http://www.hks.harvard. edu/publications/tough-call-understanding-barriers-and-impactswomens-mobile-phone-adoption-india. Accessed Oct 2018

15. Garz S, Heath R, Kipchumba E, Sulaiman M (2020) Evidence of digital financial services impacting women's economic empowerment: What explains the impacts and what is left to learn? Brac Institute of Governance and Development. http://bigd.bracu. ac.bd/all-projects/womens-economic-empowerment-and-digitalfinance/the-white-paper/

16. Pande R, Schaner S, Troyer Moore C, Stacy E (2020) A majority of India's poor women may miss COVID-19 PMJDY cash transfers. Yale Economic Growth Center. Policy Brief. http://egc. yale.edu/reaching-indias-poorest-women-covid-19-relief. Accessed 17 Apr 2020

17. Singh A, Jose J, Chouhan K, Agarwal P, Kurian V (2019) Digitisation of Self Help Groups in India. Initiative for What Works to Advance Women and Girls in the Economy
(IWWAGE) at IFMR LEAD. http://iwwage.org/wp-content/ uploads/2019/08/IWWAGE-SHG-Digitization-June-25.pdf. Accessed Apr 2019

18. Singh C, Wasdani P (2016) Finance for micro, small and medium-sized enterprises in India: sources and challenges. Asian Development Bank Institute Working Paper Series, No. 581

19. Gupta K, Kurian V, Valenti F (2020) Digitizing ecosystem payments: insights from value-chain assessments. LEAD at Krea University, Chennai

20. CGAP (2019) Digital Credit Models for Small Businesses. CGAP Research and Analysis. http://www.cgap.org/research/publica tion/digital-credit-models-small-businesses. Accessed Oct 2019

21. de Montjoye Y-A, Quoidbach J, Robic F, Pentland A (2013) Predicting personality using novel mobile phone-based metrics. In: Greenberg AM, Kennedy WG, Bos ND (eds) Social computing, behavioral-cultural modeling and prediction. Springer, pp 48-55

22. Eagle N, Pentland A, Lazer D (2009) Inferring friendship network structure by using mobile phone data. Proc Natl Acad Sci 106(36): 15274

23. Soto V, Frias-Martinez V, Virseda J, Frias-Martinez E (2011) Prediction of socioeconomic levels using cell phone records. In: Konstan JA, Conejo R, Marzo JL, Oliver N (eds) User modeling, adaptation and personalization. Springer, pp 377-388

24. Mønsted B, Mollgaard A, Mathiesen J (2018) Phone-based metric as a predictor for basic personality traits. J Res Pers 74:16-22

25. Bhandari L, Kale S, Nageswaran VA (2021) Digital lending: issues, challenges and proposed solutions. Indicus Foundation White Paper, Delhi

26. Tumbe C (2011) Remittances in India: facts and issues. IIM Bangalore Research Paper No. 331

27. Agarwalla S, Barua S, Jacob J, Varma R (2016) Savings, borrowing and remittance behaviour of migrant behaviour in Urban India. Indian Institute of Management, Ahmedabad

28. Bailey R, Goyal T, Sane R, Varma R (2021) Analysing India's KYC framework: can we do things better? Available at SSRN: https://ssrn.com/abstract=3776008

29. Seshan G, Yang D (2014) Motivating migrants: a field experiment on financial decision-making in transnational households. J Dev Econ 108:119-127

30. Datwani L, Raman A (2020) India's new approach to data sharing. CGAP Working Paper

31. Shashidhar KJ (2020) Regulatory sandboxes: decoding india's attempt to regulate Fintech disruption. ORF Research Brief, Delhi 